\title{
A Study of the Effectiveness of Edmodo on Preservice Classroom Teachers' Views of Web-Assisted Collaborative Learning Environments, Sense of Classroom Community, and Perceived Learning
}

\author{
Nazire Burcin Hamutoglu ${ }^{1 *}$, Orhan Gemikonakli ${ }^{2}$, Deniz Mertkan Gezgin ${ }^{3}$ \\ 'Department of Computer and Instructional Technology Education, Sakarya University, Sakarya, Turkey, ${ }^{2}$ Department of Design Engineering and \\ Mathematics, Middlesex University, London, United Kingdom, ${ }^{3}$ Department of Computer and Instructional Technology Education, Trakya University, \\ Edirne, Turkey \\ *Corresponding author: bhamutoglu@sakarya.edu.tr
}

\section{ABSTRACT}

This study explored the effectiveness of using web-assisted collaborative learning (COL) environments on the sense of classroom community and perceived learning (PL) using a learning platform Edmodo to enhance face-to-face learning within the framework of a community of inquiry. This study utilized pre-experimental quantitative research approaches based on a single group, pre-, and posttest model. To establish the effectiveness of the intervention, pre- and post-tests were conducted. To support the findings, independent sample t-test was used to compare the differences within groups such as gender. The findings of this study underline the importance of fostering the interaction of students with each other as well as content and instructors in online COL environments to enhance traditional classroom teaching and learning. The results show the effectiveness of the deployment of web-assisted COL environments on a sense of community of classroom and PL.

KEYWORDS: edmodo; web-assisted technologies; collaborative learning; experimental design

\section{INTRODUCTION}

$\mathbf{R}$ ecent developments in online learning environments have increased interest in the use of new approaches in higher education. This is best seen in the practices of higher education institutions (HEIs). For example, it is estimated that in the United States, nearly 3.2 million students attending HEIs are enrolled in at least one online course (Allen and Seaman, 2005). These developments have led to a change in the provision of higher education emphasizing new approaches to teaching and learning.

Volet et al. (2009) emphasized the importance of social environments and instructional contexts to support individual participation and learning. Hence, the components of an individual's interactions within a social setting are important to their learning. Within the framework of constructivist theory, social interactions are a part of the constructive process and knowledge is actively constructed by each individual (Brooks and Brooks, 1993; Tsai, 2001). Lee et al. (2017) suggested that knowledge building in collaborative learning (COL) situations can be enhanced when the appropriate tools and approaches are used in designing activities. Moore (1989) asserted the importance of interactions, stating that online learning environments enabled the interaction between learners and content and instructors.

\section{LITERATURE REVIEW AND HYPOTHESIS}

Different types of interactions affect the quality of learning differently. When compared to traditional teaching methods, the main criticism of online learning is the inadequacy of interactions (Allen and Seaman, 2011; Bullen, 1998; Ward and Newlands, 1998). Research findings point to the feeling of isolation online environments imposes on distance education students (Abrahamson, 1998; Brown, 1996; Dietz-Uhler et al., 2008; Rovai, 2002; Wegerif, 1998). This deficiency of distance learning becomes more visible when compared to interactions offered by face-to-face teaching and learning. However, Bates (2005) argued that online LER environments have a positive effect in reducing the feeling of isolation some students develop in traditional teaching and learning environments. Similarly, Steinkuehler and Williams (2006) discussed the effects of using a virtual world to build a sense of classroom community. This is due to the introversion personalities some students may have in traditional classroom environments (Harrington and Loffredo, 2010).

Rovai (2002) suggests that for promoting a better sense of community classroom, distance education courses should work to eliminate feelings of isolation. It is expected that the quality of interactions between individuals would help to remove this sense of isolation as well as increasing the sense of community 
of the classroom (SCC). Hence, it is important to explore the impact of web-assisted COL (WACL) technologies. Traditional educational systems urgently need to be enhanced through the implementation of these technologies (Liaw, 2002). Since the internet is gaining popularity in education, it provides learners with more opportunities to utilize web-based learning (Engelbrecht, 2005). Huang (2002) claims that the web has become a common tool in learner-centered or constructivist learning. When web-assisted learning environments are considered together with a constructivist approach, it is seen that this approach contributes to learning involving collaborative activities (Tsai, 2001).

In collaborative work, when individuals have a sense of belonging, they tend to work toward common goals, and this is important for the sense of classroom community. Social constructivists such as Vygotsky and Dewey argued that learners did not learn in isolation from others (Huang, 2002), and the principles of cognitive psychology are based on the fact that people naturally learn and work collaboratively in their lives (Petraglia, 1998). Previous studies have emphasized the importance of collaborative activities in increasing the sense of classroom community (Petersen et al., 2006; Zhu and Baylen, 2005). Collaborative work underlines the importance of the interaction of the learners with each other. This approach is in line with the features of online learning technologies as they promote users' critical thinking skills, enable them to collaborate, practice, share their ideas, and reflect on previous knowledge to build their perspectives. Web-based learning, E-learning, and online learning environments are representative of computer-supported COL (Liaw et al., 2008). Such environments offer students more active roles in their learning as the principles of constructivism suggest, as well as providing opportunities to contribute to a community of learners. Cho et al. (2005) stated the importance of computer-supported COL systems in promoting the acquisition and sharing of knowledge within collaborative and social communities. Dewiyanti et al. (2007) argued that learners' responsibilities to a task were positively associated with their COL experiences. In collaboration processes, it is important to feel like being part of a group and taking responsibility for one's actions. Such systems offer the best solution to problems faced by learners by supporting them to construct knowledge and encourage the exchange of ideas (Dewiyanti et al., 2007; Khosa, 2014). Bold (2006) stated that web-assisted technologies (e.g., blogs) increased the level of students' participation and created a greater SCC. Similarly, learners working toward the same goal contribute to the atmosphere of the classroom positively, and this reflects in good working relationships (Guuawardena et al., 2001).

The model of a community of inquiry (CoI) (Garrison et al., 2000) was the inspiration for the framework of this study. This model has been used in the studies of Akyol and Garrison (2011) and Shea et al. (2006) in both online and asynchronous blended learning environments. Moore (1989) identified three types of interactions such as learner-learner, learner-instructor, and learner-content. These interaction types play an important role in online environments. However, Garrison and ClevelandInnes (2010) suggested three types of CoI such as cognitive, social, and teaching presence that should be taken into account to appreciate the interaction and the quality of learning outcomes, which are consistent with the ideals of higher education. They also draw attention to the cognitive presence in online environments. Richardson and Swan (2003) investigated the role of social presence in online environments with the effects on outcomes and satisfaction of both instructors and students alike. They stressed the importance of social presence in both online educational environments and traditional educational environments. Moreover, Shea et al. (2006) highlighted the importance of teaching presence and students' sense of learning community. They argued that this improved students' sense of connectedness and learning .

Garrison et al. (2000) provide a CoI model that addresses and defines educational presence. Their study was based on the model of CoI that learners' sense of classroom community could draw attention in web-assisted environments. Furthermore, incorporating both traditional and online learning environments within the framework can further promote students' learning. Collaborative work within these environments could enhance approaches to higher education by fostering perceived learning (PL) and sense of classroom community. Rovai and Lucking (2000) defined four components of classroom community such as spirit, trust, interaction, and learning at a distance. Rovai (2002) explained that spirit is the feeling of belonging, acceptance, and group identity; trust is the feeling that the community can be trusted and feedback will be supportive and constructive; interaction is the feeling that closeness and mutual benefit result from interaction with others; and finally, learning is the feeling that knowledge and meaning are actively constructed within the community that the community enhances the acquisition of knowledge and understanding and that the educational needs of its members are being satisfied.

Hence, it becomes very important to investigate empirically the relationship between students' PL and interaction dynamics within WACL environments. Previous studies have focused on learners' preferences, perceptions, beliefs, attitudes, feelings, and self-efficacy toward information technology and web-based learning (Kagan, 1994; Liaw and Huang, 2003; Liaw, 2005; Liaw et al., 2006, Wu and Tsai, 2006; Guuawardena et al., 2001; Yang and Tsai, 2008), and instructors' attitudes and characteristics toward web-based professional developments (Deghaidy and Nouby, 2008; Kao and Tsai, 2009; Liaw et al., 2008). In addition, the benefits of COL in web-based systems for learners were investigated (Dewiyanti et al., 2007; Guuawardena et al., 2001). It is also possible to see a comparison study between web-based and classroom-based learning (Thirunarayanan \& Prado, 2001). Additionally, there are studies that have explored the instructional approach in shaping blended synchronous learning and teaching experiences (Szeto, 2015). As well as 
studies that have explored the instructional approach in shaping blended synchronous learning and teaching experiences (Szeto, 2015). Palloff et al. (2001) argued that communication and constructivist pedagogy are the key elements that allow students and instructors to develop a sense of community online, reflective of the traditional classroom. Deghaidy and Nouby (2008) investigated the effectiveness of blended e-learning on achievement, attitudes toward e-learning, and cooperativeness with a cooperative approach. Warschauer (2004) emphasized the importance of incorporating internet technologies into trainee teachers' lesson planning and providing opportunities to access information using IT. In addition, the society for information technology and teacher education, and the association for the education of teachers in science expect trainee teachers' to integrate technology into the different subjects in their classrooms (Bell, 2001). Therefore, there is a need to investigate the effects of WACL environments on the sense of classroom community and PL.

As stated, this study aimed to investigate the effects of enhancing the strengths of face-to-face teaching of pre-service classroom teachers by WACL on the sense of classroom community and PL. This study investigated how combining face-to-face and WACL environments promoted efficiency and effectiveness of teaching and learning experiences. In this respect, this study aimed to bring together various educational environments from different perspectives using constructivist approaches. Finally, it sought to foster communication and closeness among students and tutors using web-assisted technologies (Joliffe et al., 2001). As such, the participants were asked to perform given tasks in small groups, and then discuss the ideas generated on Edmodo learning platform with other groups. The instructor had control over peer discussions; monitored and directed the groups when needed.

Accordingly, this study was designed to test the following hypothesis:

- Participants' pre-test and post-test views significantly differ on the use of WACL . Specifically; participants' pre-test and post-test views significantly differ on:

1. Using the internet and classroom together (INT-CLA),

2. Using the internet in learning (INT-USE),

3. Instructional technologies and material design (ITM) courses, and

4. COL.

- Participants' pre-test and post-test views significantly differ in PL:

1. Cognitive learning (COG),

2. Affective learning (AF), and

3. Psychomotor learning (PSY).

- Participants' pre-test and post-test views significantly differ on the SCC:

1. Loyalty (LOY), and

2. Learning (LER).

Alternative hypotheses regarding student demographics associated with variables such as gender, having/not having prior experience of web-assisted collaborative activities
(WACA), and having/not having prior experience of webassisted course (WAC) are also examined.

\section{METHODOLOGY}

This study is an example of pre-experimental quantitative research approaches based on a single group, pre- and posttest model. The experimental design is shown in Table 1. To establish the effectiveness of the experimental work, pre- and post-test was conducted to find out the differences in WACL, SCC, and PL of the participants' views before and after experimenting with the use of Edmodo.

\section{The Sample}

The sample used is representative of the pre-service teacher population of the 2015-2016 spring term cohort of the Faculty of Education, Sakarya University, Adapazarı, Turkey. In forming the sample group, the main criteria were that potential participants were studying in a program that required collaborative work to develop technology-based projects. This is in line with the governmental policy of investment toward enriching educational environments with the use of technology in Turkey. Possessing these characteristics, the ITM course was selected. Hence, potential participants were studying in academic programs incorporating this course as a compulsory component. Accordingly, the sample group consisted of

$\begin{aligned} & \text { Table 1: The pre-experimental single group pre-test and } \\
& \text { post-test design }\end{aligned}$
\begin{tabular}{lccc}
\hline Group & Pre-test & Process & Post-test \\
\hline G & O1 & $\mathrm{X}$ & $\mathrm{O} 2$ \\
\hline
\end{tabular}

\begin{tabular}{lcc}
\hline \multicolumn{3}{l}{ Table 2: The participants according to gender } \\
\hline Gender & Frequency (f) & Percentage (\%) \\
\hline Female & 45 & 77.6 \\
Male & 13 & 22.4 \\
Total & 58 & 100 \\
\hline
\end{tabular}

Table 3: The participants with/without prior experiences of WACA

\begin{tabular}{lcc}
\hline WACA & Frequency (f) & Percentage (\%) \\
\hline Yes & 7 & 12.1 \\
No & 51 & 87.9 \\
Total & 58 & 100 \\
\hline \multicolumn{2}{l}{ WACA: Web-assisted collaborative activities }
\end{tabular}

Table 4: The participants with/without prior experiences of WAC

\begin{tabular}{lcc}
\hline WAC & Frequency (f) & Percentage (\%) \\
\hline Yes & 56 & 96.6 \\
No & 2 & 3.4 \\
Total & 58 & 100 \\
\hline
\end{tabular}

WAC: Web-assisted course 
45 female and 13 male participants randomly chosen from the population of pre-service classroom teachers. Tables 2-4 present information on the sample group.

\section{Data Collection}

Before data collection, this study was granted ethical consent from the university, and then participants provided informed consent. Then, data were collected on the following three different scales: WACL, SCC, and PL.

\section{The WACL scale}

The WACL scale was developed by Demirbağ and Kartal (2011) as an instrument to assess students' views. The WACL consists of the INT-CLA, INT-USE, and the issue of coordination chemistry, web pages, and COL sub-dimensions. In this study, the subdimensions INT-CLA, INT-USE, and COL have been used in the original form presented in the scale, the topics under coordination chemistry were adapted to the course area the experiment applied to and used after collecting expert views. The instrument has been developed as a 5-point Likert Scale changing from "strongly Disagree" (1) to "strongly agree" (5). There are six items in the INT-CLA sub-dimension, an example of which is "I prefer the joint use of classroom and internet environments during teaching and learning activities." Similarly, there are nine items in INTUSE sub-dimension such as "I like to use the internet for lessons." The sub-dimension COL consists of 14 items such as "collaborative activities help improving myself." Finally, there are six items in ITM subdimension such as "I would like to have web-assisted activities during the ITM classes."

Regarding teaching presence, students' perception about using web-assisted technologies in support of face-to-face learning will map within the WACL instrument which is necessary for both instructors and students to increase the interaction of the two sides. Instructors could follow students to check their progress and encourage them to share their ideas within groups. It is also possible to direct students to the new research areas on web-based technologies. These technologies are supportive of the traditional methods of enhancing learning by the use of new pedagogic approaches.

\section{The PL scale}

The Turkish adaptation of the PL scale developed by Rovai et al. (2009) was done by Albayrak et al. (2014) working with students engaged in face-to-face and online learning. The PL scale consists of nine items with three sub-dimensions. The subdimensions are COG, AF, and PSY. The subdimensions consist of three items each. The original of the scale is a 7-point Likert scale where each item is sorted from one to seven ranging from "not at all" to "very much so," respectively. Overall, the three maximum-likelihood subdimensions accounted for $67 \%$ of the variance of the data. The Eigenvalues and variances of the sub-dimensions of the scale are as follows: 3.56 and $39.52 \%, 1.32$ and $14.68 \%$, and 1.10 and $12.25 \%$ for COG, AF, and PSY, respectively. The Cronbach's Alpha value used for the whole of the PL scale was 0.83 . The values for the same were $0.65,0.66$, and 0.72 for the subdimensions $\mathrm{COG}, \mathrm{AF}$, and
PSY, respectively. The findings obtained from the adaptation process showed that the scale's psychometric characteristics were applicable to the target culture.

PL scale was used to measure the perception of learners on web-assisted collaborative processes. It is challenging to assess students' learning in online environments. To achieve this, students were asked to give an assessment of prior learning and their experiences of PL through the use of online learning environments (Caspi and Blau, 2008). Therefore, it is believed that the individual's PL in online COL environments is also important. The scale developed by Rovai (2009) is important due to incorporating three different dimensions of learning covering face-to-face as well as distance learning together with a direct focus on PL. According to these, the interaction of individuals, review of own ideas, sense of belonging, and $\mathrm{PL}$ are related to each other.

\section{The SCC scale}

The SCC scale developed by Rovai (2002) has been adapted to the Turkish context by Ozturk (2009). The adapted scale consists of 13 items, each having two subdimensions which are LOY (partially combining spirit, trust, and interaction given in the original scale) and LER. The adaptation resulted in six and seven items in LOY and LER subdimensions, respectively. The answers associated with the 5-point Likert scale change from "strongly disagree" (1) to "strongly agree" (5). In the analysis, the reverse items were considered. The factor loadings of the LOY subdimension of the scale varied between 0.89 and 0.86 accounting for $14.0 \%$ of the variance. Similarly, for the LER subdimension, the range of factor loadings was between 0.79 and 0.55 accounting for $36.61 \%$. The Cronbach's Alpha value was 0.77 for LOY and 0.84 for LER. The same was 0.85 for the scale itself. The values given above confirm that the adapted scale was valid and reliable.

\section{Data Analysis}

In the analysis of the data collected from the sample group, SPSS 20 has been used. These analyses include tests such as paired sample $t$-test and descriptive statistical analysis.

The process

In this section, the intervention design process of the study is explained.

1. Step 1

Before the study's intervention, a pre-test was used to take the views of the sample group on WCAL, SCC, and PL using the relevant scales.

2. Step 2

The participating pre-service teachers were organized to work on Edmodo collaboratively. The work involved sharing teaching and learning materials and ideas as well as using the discussion board collaboratively in performing given tasks for 5 weeks. They were introduced to a new task each week. The process was controlled by an instructor and directed as needed.

3. Step 3

A post-test similar to the pre-test was conducted collecting the views of the participants. This enabled 
the assessment of the effectiveness of the intervention through the comparison of the participants' views before and after the experiment.

In summary, the following approach has been used for data analysis. Analyses were carried out for both paired and independent samples t-tests. In the case of paired samples, the $t$-test helped to identify the changes in the use of the subject group for pre- and post-tests. Independent samples t-test was performed to compare the differences of groups such as gender, prior experience of WACLA or lack of it, and prior experience on WAC or lack of it. In the latter case, the comparisons were done for both pre- and post-test views separately. For both cases, the analysis was also extended to subdimensions. The values given in Table 5 show the distribution of normality (i.e., $\rho>0.05$ ), confirming that the use of a parametric test is valid.

\section{Edmodo learning platform and planning collaborative activities}

Edmodo allows for the use of various educational applications. It is a free social learning network offering sharing resources, communication, and collaboration for students, teachers, and alike. Besides supporting text messaging, alert boards, blogs, and uploading file, Edmodo also facilitates networking with useful contacts and access to resources for students to fulfill their potential. Edmodo is the most secure and reliable social network platform supporting educational activities (Weber, 2012). Its functions are enriched with analytical tools enabling the monitoring, assessment, and management of students (Edmodo, 2018).

Edmodo was used in this study to empower students to work collaboratively. The collaboration was achieved through sharing ideas and work, forming discussion platforms, interactions, and communicating effectively. An instructor was in charge of the process monitoring and leading student activities and ensuring participation from all to prevent the sense of isolation for vulnerable students. The classroom climate was enhanced by the introduction of web-assisted systems in coherence with the pedagogical framework of COL. The tasks were given to the students on Edmodo following the principles of interaction (Johnson and Johnson, 1996). These include:

Giving and receiving help and assistance, exchanging resources and information, giving and receiving feedback on

\begin{tabular}{|c|c|c|c|c|c|c|c|}
\hline \multirow[t]{2}{*}{ Scale } & \multirow[t]{2}{*}{ Test } & \multicolumn{3}{|c|}{ Kolmogorov-Smirnov } & \multicolumn{3}{|c|}{ Shapiro-Wilk } \\
\hline & & Statistic & df & $\rho$ & Statistic & df & $\rho$ \\
\hline \multirow[t]{2}{*}{ WACL } & Pre-test & 0.055 & 58 & $0.200^{*}$ & 0.988 & 58 & 0.852 \\
\hline & Post-test & 0.102 & 58 & $0.200 *$ & 0.976 & 58 & 0.297 \\
\hline \multirow[t]{2}{*}{$\mathrm{SCC}$} & Pre-test & 0.102 & 58 & $0.200 *$ & 0.979 & 58 & 0.397 \\
\hline & Post-test & 0.099 & 58 & $0.200 *$ & 0.983 & 58 & 0.608 \\
\hline \multirow[t]{2}{*}{ PL } & Pre-test & 0.064 & 58 & $0.200^{*}$ & 0.980 & 58 & 0.473 \\
\hline & Post-test & 0.112 & 58 & 0.066 & 0.973 & 58 & 0.225 \\
\hline
\end{tabular}

taskwork and teamwork behavior, challenging each other's reasoning, advocating increased efforts to achieve, mutually influencing each other's reasoning and behavior, engaging in the interpersonal and small group skills needed for AF teamwork, and processing how effectively group members are working together, and how the group's effectiveness can be continuously improved (Johnson and Johnson, 1996, p. 1017-1044).

Following the assignment of a task to groups, each task was discussed during the week. The main task issues were: Work collaboratively to discuss (i) the importance of educational technologies and learning materials in teaching; where it comes from and where it goes, and how it affects learning, (ii) how individual differences should be considered while developing learning materials, (iii) the importance of digital nativeness in online environments, and (iv) the importance of connecting with and contributing to the government supported FATIH Project in education. FATIH is the abbreviated name of a government project in education meaning "increasing opportunities and improving technology" (FATIH, 2016) and (v) how to apply existing and as well as new learning and teaching approaches to online environments.

\section{FINDINGS}

SPSS was used to analyze the effectiveness of the experimental design. The findings are summarized in Tables 6-10. Tables 6-10 only show significant results. The rest of the findings have been omitted from the tables.

According to Table 6, the pre- and post-test results obtained from the answers given by the pre-service teachers to the tools WCAL, SCC, and PL clearly show that there were significant differences between pre-test and post-test findings (WCAL: $\mathrm{t}(57)=-14.144, \rho<0.001 ; \mathrm{SCC}: \mathrm{t}(57)=6.055, \rho<0.001$; and PL: $\mathrm{t}(57)=2.849, \rho<0.01)$. While the pre-test WACL average score of the pre-service teachers was $\mathrm{M}=121.10$, it increased to $M=143.22$ in the post-test. Besides this, SCC and $\mathrm{PL}$ average scores dropped from $\mathrm{M}=42.84$ and $\mathrm{M}=46.84$ to $\mathrm{M}=39.72$ and $\mathrm{M}=43.38$, respectively. It is thought that the drop in SCC and PL average score is due to reverse items of scales. These findings show that this study's intervention had

\begin{tabular}{|c|c|c|c|c|c|c|c|}
\hline Scale & Test & N & $X$ & $S$ & Sd & $t$ & $\rho$ \\
\hline \multirow[t]{2}{*}{ WACL } & Pre-test & 58 & 121.10 & 9.0 & 57 & -14.144 & 0.000 *** \\
\hline & Post-test & 58 & 143.22 & 9.24 & & & \\
\hline \multirow[t]{2}{*}{$\mathrm{SCC}$} & Pre-test & 58 & 42.84 & 3.22 & 57 & 6.055 & $0.000 * * *$ \\
\hline & Post-test & 58 & 39.72 & 2.94 & & & \\
\hline \multirow[t]{2}{*}{ PL } & Pre-test & 58 & 46.84 & 7.72 & 57 & 2.849 & $0.006^{* *}$ \\
\hline & Post-test & 58 & 43.37 & 4.89 & & & \\
\hline
\end{tabular}




\begin{tabular}{|c|c|c|c|c|c|c|c|c|}
\hline Scale & Subdimensions & Test & $\mathbf{N}$ & $X$ & $\mathbf{S}$ & Sd & $t$ & $\rho$ \\
\hline \multirow[t]{8}{*}{ WACL } & \multirow[t]{2}{*}{ INT-CLA } & Pre-test & 58 & 21.25 & 1.95 & \multirow[t]{8}{*}{57} & \multirow[t]{2}{*}{-4.923} & \multirow[t]{2}{*}{$0.000^{* * *}$} \\
\hline & & Post-test & 58 & 23.68 & 3.04 & & & \\
\hline & \multirow[t]{2}{*}{ INT-USE } & Pre-test & 58 & 31.96 & 4.12 & & \multirow[t]{2}{*}{-3.627} & \multirow[t]{2}{*}{$0.001 * *$} \\
\hline & & Post-test & 58 & 34.74 & 4.44 & & & \\
\hline & \multirow[t]{2}{*}{ ITM } & Pre-test & 58 & 19.48 & 1.78 & & \multirow[t]{2}{*}{-10.174} & \multirow[t]{2}{*}{$0.000^{* * *}$} \\
\hline & & Post-test & 58 & 24.17 & 3.06 & & & \\
\hline & \multirow[t]{2}{*}{$\mathrm{COL}$} & Pre-test & 58 & 48.39 & 3.98 & & \multirow[t]{2}{*}{-14.383} & \multirow[t]{2}{*}{$0.000 * * *$} \\
\hline & & Post-test & 58 & 60.62 & 5.59 & & & \\
\hline \multirow[t]{4}{*}{$\mathrm{SCC}$} & \multirow[t]{2}{*}{ LOY } & Pre-test & 58 & 21.89 & 2.38 & \multirow[t]{4}{*}{57} & \multirow[t]{2}{*}{-2.811} & \multirow[t]{2}{*}{$0.007 * *$} \\
\hline & & Post-test & 58 & 23.0 & 2.16 & & & \\
\hline & \multirow[t]{2}{*}{ LER } & Pre-test & 58 & 20.94 & 1.80 & & \multirow[t]{2}{*}{13.705} & \multirow[t]{2}{*}{$0.000 * * *$} \\
\hline & & Post-test & 58 & 16.72 & 2.24 & & & \\
\hline \multirow[t]{6}{*}{ PL } & \multirow[t]{2}{*}{ COG } & Pre-test & 58 & 15.46 & 2.80 & \multirow[t]{6}{*}{57} & \multirow[t]{2}{*}{4.698} & \multirow[t]{2}{*}{$0.000 * * *$} \\
\hline & & Post-test & 58 & 13.48 & 1.80 & & & \\
\hline & \multirow[t]{2}{*}{$\mathrm{AF}$} & Pre-test & 58 & 15.24 & 3.13 & & \multirow[t]{2}{*}{-1.513} & \multirow[t]{2}{*}{0.136} \\
\hline & & Post-test & 58 & 16.10 & 2.88 & & & \\
\hline & \multirow[t]{2}{*}{ PSY } & Pre-test & 58 & 16.13 & 2.67 & & \multirow[t]{2}{*}{5.063} & \multirow[t]{2}{*}{$0.000 * * *$} \\
\hline & & Post-test & 58 & 13.79 & 1.91 & & & \\
\hline
\end{tabular}

$* * * \rho<0.001, * * \rho<0.01, * \rho<0.05$, WACL: Web-assisted COL, SCC: Sense of community of classroom, PL: Perceived learning, INT-CLA: Internet and classroom together, INT-USE: Using the internet, ITM: Instructional technologies and material design, COL: Collaborative learning, LOY: Loyalty, COG: Cognitive, AF: Affective, PSY: Psychomotor

Table 8: T-test results obtained from subdimensions of the scales WACL, SCC, and PL for independent samples when gender is considered

\begin{tabular}{|c|c|c|c|c|c|c|c|c|c|}
\hline Scale & Sub-dimensions & Test & Gender & N & M & $\mathbf{S}$ & Sd & $t$ & $\rho$ \\
\hline \multirow[t]{2}{*}{ PL } & $\mathrm{AF}$ & Pre-test & Female & 45 & 14.75 & 3.07 & 56 & -2.274 & $0.027^{*}$ \\
\hline & & & Male & 13 & 16.92 & 2.84 & & & \\
\hline
\end{tabular}

$* * * \rho<0.001, * * \rho<0.01,{ }^{*} \rho<0.05$, AF: Affective, PL: Perceived learning, WACL: Web-assisted COL, SCC: Sense of community of classroom

an important effect in increasing the views of participants in relation to WACL, SCC, and PL.

In Table 7, the pre- and post-test results obtained from the responses of the pre-service teachers to the sub-dimensions of the tools WCAL, SCC, and PL clearly show that there were significant differences between pre-test and post-test findings (INT-CLA: $\mathrm{t}(57)=-4.923, \rho<0.001$; INT-USE: $\mathrm{t}(57)=3.627, \rho<0.01$; ITM: $\mathrm{t}(57)=-10.174, \rho<0.001$; COL: $\mathrm{t}(57)=-10.174, \rho<0.001 ;$ LOY: $\mathrm{t}(57)=-2.811, \rho<0.01$; LER: $\mathrm{t}(57)=13.705, \rho<0.001$; AF: $\mathrm{t}(57)=4.698, \rho<0.001$; and PSY: $\mathrm{t}(57)=5.063, \rho<0.001)$ with the exception of the AF subdimension $(\mathrm{t}(57)=-1.513, \rho>0.05)$. Among the pretest average of the scales' subdimensions, INT-CLA changed from $M=21.25$ in the pre-test to $M=23.68$ for the post-test. Similarly, for INT-USE the change was from $\mathrm{M}=31.96$ to $\mathrm{M}=34.74$; for ITM it raised from $\mathrm{M}=19.48$ to $\mathrm{M}=24.17$, and for LOY the increase was from $\mathrm{M}=21.89$ to $\mathrm{M}=23.0$. The highest change was seen on the COL subdimension; it changed from $M=48.39$ to $M=60.62$. Besides this, $C O G$, LER, and PSY subdimensions average scores dropped from $M=15.4655, M=20.94$, and $M=6.13$ to $M=13.48$, $M=16.72$, and $M=13.79$, respectively. Although this may look interesting, it is thought that the drop in average scores is due to reverse items of scales.
In Table 8, it is clearly seen that considering pre- and post-test results; there is a significant difference between male and female responses for the subdimension AF through the views of pre-service teachers on pre-test results $(\mathrm{t}(56)=-2.274$, $\rho<0.05)$. According to the findings it is possible to say that male scores $(M=16.92)$ were higher than female scores $(\mathrm{M}=14.75)$ for the AF sub-dimension.

Table 9 presents a significant difference between participants having and not having prior experiences of WACLA when the subdimension AF was considered $(\mathrm{t}(56)=2.028, \rho<0.05)$. According to the findings, the participants having prior experiences of WACLA scored higher $(\mathrm{M}=17.42)$ than those who lacked such experiences $(M=15.19)$.

According to Table 10, the pre-test results obtained for the tools WACL, SCC, and PL clearly showed that there were significant differences between having prior experience of WAC and lack of it when AF and INT-USE were considered $($ AF: $\mathrm{t}(56)=-2.261, \rho<0.05$ and INT-USE: $\mathrm{t}(56)=-2.992$, $\rho<0.01)$. For AF and INT-USE, the comparative scores of having and not having prior experience of WAC were higher $(\mathrm{M}=15.07)$ and $(\mathrm{M}=20.00)$ than the others $(\mathrm{M}=31.67)$ and $(M=40.00)$ indicating higher scores for those with prior experience of WAC for subdimensions. 
Table 9: T-test results obtained from subdimensions of the scales WACL, SCC, and PL for independent samples when prior experiences of WACLA considered

\begin{tabular}{llllcccccc}
\hline Scale & Subdimensions & Test & WACLA & N & M & S & Sd & t & $\boldsymbol{\rho}$ \\
\hline PL & AF & Pre-test & Yes & 7 & 17.42 & 2.50 & 56 & 2.028 & $0.047^{*}$ \\
& & & No & 51 & 15.19 & 2.75 & & & \\
\hline
\end{tabular}

${ }^{* * *} \rho<0.001,{ }^{*} \rho<0.01,{ }^{*} \rho<0.05$, AF: Affective, PL: Perceived learning, WACL: Web-assisted COL, SCC: Sense of community of classroom

Table 10: T-test results obtained from subdimensions of the scales WACL, SCC, and PL for independent samples when prior experiences of WAC considered

\begin{tabular}{|c|c|c|c|c|c|c|c|c|c|}
\hline Scale & Sub-dimensions & Test & WAC & $\mathbf{N}$ & M & $S$ & Sd & $t$ & $\rho$ \\
\hline \multirow[t]{2}{*}{ PL } & $\mathrm{AF}$ & Pre-test & Yes & 56 & 15.07 & 3.05 & 56 & -2.261 & $0.028 *$ \\
\hline & & & No & 2 & 20.00 & 1.41 & & & \\
\hline \multirow[t]{2}{*}{ WACL } & INT-USE & Pre-test & Yes & 56 & 31.67 & 3.89 & 56 & -2.992 & $0.004 * *$ \\
\hline & & & No & 2 & 40.00 & 0.00 & & & \\
\hline
\end{tabular}

$* * * \rho<0.001, * * \rho<0.01, * \rho<0.05$, AF: Affective, PL: Perceived learning, WACL: Web-assisted COL, SCC: Sense of community of classroom, WAC: Web-assisted course, INT-USE: Using the internet

\section{DISCUSSION AND CONCLUSION}

To enhance the traditional educational methods in higher education, web-assisted technologies can provide alternative ways and professional developments on innovative pedagogical strategies such as COL environments. This study explored pre-service teachers' views toward PL and community of the classroom through using web-assisted technologies and discussed the findings. The study highlighted the effect of webassisted COL environments on the SCC and PL. Experiments were set up conducting pre-tests and post-tests on pre-service teachers introduced to the use of the technologies in question. A social learning network, Edmodo was used as a platform in this context. The sample was chosen from a population of preservice teachers from Sakarya University who were expected to be introduced to web-assisted technologies and work on technological projects as part of their studies. Results were then analyzed to show the effectiveness of the experimental process on the SCC, and PL. Huang et al. (2010) studied similar concepts using social networking sites as a supplementary tool instead, reporting positive feedback from the majority of participants. The findings of our study correlate with this. Pre-test and posttest results clearly showed that the participants' views on WACL, SCC, and PL significantly changed following the experiment.

The results obtained from pre- and post-tests showed the effectiveness of the experimental process on changing participants' views on WACL and PL. In comparison to the relevant literature, the findings are consistent with the studies which show the effectiveness of web-based technologies in collaborative environments (McDonald, 2002; Rafaeli et al., 2004). It is believed that web-based technologies support sharing knowledge and can enhance better teaching and learning. Moreover, various opportunities are offered by the systems for both instructors and learners such as assessing peers' work and exchanging information in their studies.

In addition, pre- and post-test results for the subdimensions of the instruments such as INT-CLA, INT-USE, ITM, and COL of
WACL; AF, COG, and PSY of PL; and LOY and LER of SCC were analyzed. The findings showed that the subdimensions of instruments were significantly different $(\rho<0.001 ; \rho<0.01)$ with the exception of AF of PL. Actually this finding can stem from attitudes of students toward the computer, internet and other technologies relevant to AF learning. This outcome supports findings previously published (Triandis, 1971), where it is suggested that attitudes consist of AF, cognitive, and behavioral components. Moreover, Liaw (2002) indicated in his studies that computer-related experiences bring a more positive perception to computer and web technologies. According to Thompson et al. (1991) anxiety, confidence, and liking represent the AF part of the attitude. It is possible to suggest through the participants' views that the subjects of the study are digital natives born into technology and have confidence in using technology due to having more experience with computer and web technologies. The insignificant findings of pre- and post-test results on AF may be due to the familiarity of these technologies to the participants.

Demographic characteristics of the subjects such as gender, having/or not having prior experiences on WACA, and having/ or not having prior experiences on WAC were analyzed through the subdimensions of the instruments used. The findings showed that gender made a significant difference in AF. Furthermore, it was seen that males' AF learning scores were higher than those of their female counterparts. These findings are in conformance with the studies of Liaw (2002), Chen (1986), Fetler (1985), and Temple and Lips (1989) indicating that males have a more positive perception, as well as the study of Meier and Lambert (1991) showing less anxiety for males. Furthermore, Durndell and Thomson (1997), Durndell and Hagg (2002), and Whitely (1997) showed that males were more experienced in using computers than females. Finally, Tsai (2008) revealed that males tend to prefer internet-based environments more than females do which was confirmed by the findings of this study. Various studies reported the effect of teacher immediacy on AF learning (Gorham, 1988; Kearney 
et al., 1985; McCroskey et al., 1996). It has been shown that this is also the case for web-assisted environments.

Considering the subjects having/or not having prior experiences on WACA, the analysis showed significant differences in the case of COG. The findings showed that the participants who had previous experience of WACA were better in COG than the others. Various studies previously reported on the importance of COG of those with previous exposure to such technologies (Abbey, 1999; Cook, 2005; Hubbard and Levy, 2016; Hwang et al., 2008). The consistency of the results obtained with those reported in literature shows the importance of experience in COG .

Finally, having any previous exposure to WACs was seen as an identifiable variable on AF and INT-USE. Interestingly, the findings show that AF and INT-USE scores of the subjects who had no previous experience of WACs were higher than the others. However, it is possible to explain these findings with previously reported studies (Anderson, 1996; Igbaria and Parasuraman, 1989; Yaghi and Abu-Saba, 1998). In light of the studies it can be stated that anxiety toward computers relates to the AF dimension and it is possible to overcome this through more and frequent exposure to the use of computers. The findings showed that the participants who had not previously taken WACs had higher scores on AF. It is worth noting that the participants who had not taken any WAC previously had high INT-USE scores. These findings were explained in the study of Tsai (2008), which emphasized that students with more internet experiences were keener on the features of the constructivist internet-based learning environments than those with less internet experiences.

This study highlighted the effects of WACL environments used in enhancing traditional classroom teaching on SCC and PL. The findings highlight that it is worth using WACL environments to improve students' PL and support the SCC. In addition, it underlines the importance of using web-assisted technologies in a collaborative framework for the subject of study. To monitor the effectiveness of WACL environments, it is possible to conduct longitudinal and experimental studies to see the students' behavior in the long term. Moreover, other online learning environments could be used as pedagogical approaches in education and qualitative studies may be conducted to support the findings of research. Finally, as a limitation of the study, the effectiveness of the process has not been tested with reference to the achievements of the participants. Future research can analyze the impact of webassisted collaborative environments by comparing participants' pre- and post-test performances. This can be extended to seeing the impact of peer assessment on SCC and PL when using web-assisted environments in a capacity of enhancing traditional classroom environment.

\section{REFERENCES}

Abbey, B., (Ed.). (1999). Instructional and Cognitive Impacts of Web-Based Education. London, United Kingdom: Idea Group Publishing.
Abrahamson, C.E. (1998). Issues in interactive communication in distance education. College Student Journal, 32(1), 33-43.

Akyol, Z., \& Garrison, D.R. (2011). Understanding cognitive presence in an online and blended community of inquiry: Assessing outcomes and processes for deep approaches to learning. British Journal of Educational Technology, 42(2), 233-250.

Albayrak, E., Güngören, Ö.C., \& Horzum, M.B. (2014). Adaptation of Perceived Learning Scale to Turkish. Ondokuz Mayls Faculty of Education Journal, 33(1), 1-14.

Allen, I.E., \& Seaman, J. (2005). Making the Grade: Online Education in the United States, 2006. Needham, MA: Sloan-C.

Allen, I.E., \& Seaman, J. (2011). Going the Distance: Online Education in the United States. BABSON Survey Research Group, the Sloan Consortium. Available from: http://www.onlinelearningsurvey.com/ highered.html. [Last retrieved on 2018 Dec 02].

Anderson, A.A. (1996). Predictors of computer anxiety and performance in information systems. Computers in Human Behavior, 12(1), 61-77.

Bates, A.W. (2005). Technology, E-learning and Distance Education. London, UK: Routledge.

Bell, L. (2001). Preparing tomorrow's teachers to use technology: Perspectives of the leaders of twelve national education associations. Contemporary Issues in Technology and Teacher Education, 1(4), 517-534. Available from: http://www.editlib.org/index.cfm/files/ paper_10740.pdf?fuseaction=Reader.DownloadFullText\&paper_ id $=10740$. [Last retrieved 2016 Sep 05].

Bold, M. (2006). Use of wikis in graduate course work. Journal of Interactive Learning Research, 17(1), 5-14.

Brooks, J.G., \& Brooks, M.G. (1993). The Case for Constructivist Classrooms. Alexandria, VA: Association for Supervision and Curriculum Development.

Brown, K.M. (1996). The role of internal and external factors in the discontinuation of off-campus students. Distance Education, 17(1), 44-71.

Bullen, M. (1998). Participation and critical thinking in online university distance education. Journal of Distance Education, 13(2), 1-32.

Caspi, A., \& Blau, I. (2008). Social presence in online discussion groups: Testing three conceptions and their relations to perceived learning. Social Psychology of Education, 11(3), 323-346.

Chen, M. (1986). Gender and computers: The beneficial effects of experience on attitudes. Journal of Educational Computing, 2(3), 265-282.

Cho, H., Lee, J.S., Stefanone, M., \& Gay, G. (2005). Development of computer supported collaborative social networks in a distributed learning community. Behaviour and Information Technology, 24(6), 435-447.

Cook, D.A. (2005). Learning and cognitive styles in web-based learning: Theory, evidence, and application. Academic Medicine, 80(3), 266-278.

Deghaidy, H.E., \& Nouby, A. (2008). Effectiveness of a blended e-learning cooperative approach in an Egyptian teacher education programme. Computers and Education, 51(3), 988-1006.

Demirbağ, B., \& Kartal, M. (2011). Students' opinions about web assisted collaborative learning in inorganic chemistry. Buca Faculty of Education Journal, 29, 36-49.

Dewiyanti, S., Brand-Gruwel, S., Jochems, W., \& Broers, N.J. (2007). Students' experience with collaborative learning in asynchronous computer-supported collaborative learning environments. Computers in Human Behavior, 23(1), 496-514.

Dietz-Uhler, B., Fisher, A., \& Han, A. (2008). Designing online courses to promote student retention. Journal of Educational Technology Systems, 36(1), 105-112.

Durndell, A., \& Hagg, Z. (2002). Computer self efficacy, computer anxiety, attitudes towards the internet and reported experience with the internet, by gender, in an East European sample. Computers in Human Behavior, 18(5), 521-535.

Durndell, A., \& Thomson, K. (1997). Gender and computing: A decade of change. Computers and Education, 28(1), 1-9.

Edmodo. (2018). The World's Largest Learning Community. Available from: https://www.edmodo.com/?language=en. [Last retrieved 2018 Dec 02].

Engelbrecht, E. (2005). Adapting to changing expectations: Post-graduate students' experience of an e-learning tax program. Computers and Education, 45, 217-229. 
Fetler, M. (1985). Sex differences on California state-wide assessment of computer literacy. Sex Roles, 13, 181-186.

Garrison, D.R., \& Cleveland-Innes, M. (2010). Facilitating cognitive presence in online learning: Interaction is not enough. American Journal of Distance Education, 19(3), 133-148.

Garrison, D.R., Anderson, T., \& Archer, W. (2000). Critical inquiry in a textbased environment: Computer conferencing in higher education. The Internet and Higher Education, 2(3), 87-105.

Gorham, J. (1988). The relationship between verbal teacher immediacy behaviors and student learning. Communication Education, 37, 40-53.

Guuawardena, N.C., Nola, A.C., Wilson, P.L., Lopez-Islas, J.R., RamirezAngel, N., \& Megchun-Alpizar, R.M. (2001). A crosscultural study of group process and development in online conferences. Distance Education, 22, 85-121.

Harrington, R., \& Loffredo, D.A. (2010). MBTI personality type and other factors that relate to preference for online versus face-to-face instruction. The Internet and Higher Education, 13(1), 89-95.

Huang, J.J., Yang, S.J., Yueh-Min, H., \& Hsiao, I.Y. (2010). Social learning networks: Build mobile learning networks based on collaborative services. Journal of Educational Technology and Society, 13(3), 78.

Huang, M.H. (2002). Toward constructivism for adult learners in online learning environments. British Journal of Educational Technology, 33(1), 27-37.

Hubbard, P., \& Levy, M. (2016). Theory in computer-assisted language learning research and practice. In: Farr, F., \& Murray, L., (Eds.), The Routledge Handbook of Language Learning and Technology. Milton Park, Abingdon, Oxon: Routledge. pp. 50-64.

Hwang, W.Y., Wang, C.Y., Hwang, G.J., Huang, Y.M., \& Huang, S. (2008). A web-based programming learning environment to support cognitive development. Interacting with Computers, 20(6), 524-534.

Igbaria, M., \& Parasuraman, S. (1989). A path analytic study of individual characteristics, computer anxiety and attitudes toward microcomputers. Journal of Management, 15, 373-388.

Johnson, D.W., \& Johnson, R.T. (1996). Cooperation and the use of technology. In: Jonassen, D.H., (Ed.), Handbook of Research for Educational Communications and Technology. New York: Simon and Schuster Macmillan. pp. 1017-1044.

Joliffe, A., Ritter, J., \& Stevens, D. (2001). The Online Learning Handbook: Developing and using Web-Based Learning. United Kingdom: Springer.

Kagan, S. (1994). Cooperative Learning. San Juan Capistrano, CA: Resources for Teacher.

Kao, P.C., \& Tsai, C.C. (2009). Teachers' attitudes toward web-based professional development, with relation to Internet self-efficacy and beliefs about web-based learning. Computers and Education, 53(1), 66-73.

Kearney, P., Plax, T.G., \& Wendt-Wasco, N.J. (1985). Teacher immediacy for affective learning in divergent college classes. Communication Quarterly, 33(1), 61-74.

Khosa, D.K. (2014). Processes of Metacognitive Regulation and Knowledge Co-Construction in Case-Based Collaborative Learning at University. (Unpublished Doctoral Dissertation, Murdoch University, Australia). Available from: http://www.researchrepository.murdoch.edu.au/id/ eprint/22866. [Last retrieved on 2018 Dec 02].

Lee, L., Lajoie, S.P., Poitras, E.G., Nkangu, M., \& Doleck, T. (2017). Coregulation and knowledge construction in an online synchronous problem based learning setting. Education and Information Technologies, 22(4), 1623-1650.

Liaw, S.S. (2002). An internet survey for perceptions of computers and the world wide web: Relationship, prediction, and difference. Computers in Human Behavior, 18(1), 17-35.

Liaw, S.S. (2005). Developing a web assisted knowledge construction system based on the approach of constructivist knowledge analysis of tasks. Computers in Human Behavior, 21(1), 29-44.

Liaw, S.S., \& Huang, H.M. (2003). An investigation of users attitudes toward search engines as an information retrieval tool. Computers in Human Behavior, 19(6), 751-765.

Liaw, S.S., Chang, W.C., Hung, W.H., \& Huang, H.M. (2006). Attitudes toward search engines as a learning assisted tool: Approach of Liaw and Huang's research model. Computers in Human Behavior, 22, 177-190.

Liaw, S.S., Chen, G.D., \& Huang, H.M. (2008). Users' attitudes toward
Web-based collaborative learning systems for knowledge management. Computers and Education, 50(3), 950-961.

McCroskey, J.C., Sallinen, A., Fayer, J.M., Richmond, V.P., \& Barraclough, R.A. (1996). Nonverbal immediacy and cognitive learning: A crosscultural investigation. Communication Education, 45, 200-211.

McDonald, A.S. (2002). The impact of individual differences on the equivalence of computer-based and paper-and-pencil educational assessments. Computers and Education, 39(3), 299-312.

Meier, S.T., \& Lambert, M.E. (1991). Psychometric properties and correlates of three computer aversion scales. Behavior Research Methods, Instruments, and Computers, 23(1), 9-15.

Moore, M.G. (1989). Three types of interaction. The American Journal of Distance Education, 3(2), 1-6.

Movement of Enhancing Opportunities and Improving Technology (FATIH). (2016). FATIH Gateway to the Future in Education. Available from: http://www.fatihprojesi.meb.gov.tr. [Last retrieved on 2018 Dec 02].

Ozturk, E. (2009). Adaptation of the classroom community index: The validity and reliability study. Hacettepe University Journal of Education, $36,193-202$

Palloff, R.M., Pratt, K., \& Stockley, D. (2001). Building learning communities in cyberspace: Effective strategies for the online classroom. The Canadian Journal of Higher Education, 31(3), 175.

Petersen, S.A., Chabert, G., \& Divitini, M. (2006). Language learning: Design considerations for mobile community blogs. IADIS International Conference Mobile Learning, 14-15. Available from: http://www.citeseerx.ist.psu.edu/viewdoc/ download?doi $=10.1 \cdot 1.159 .6177 \&$ rep $=$ rep $1 \&$ type $=$ pdf. [Last accessed on 2018 Aug 07].

Petraglia, J. (1998). The real world on a short leash: The (mis)application of constructivism to the design of educational technology. Educational Technology Research and Development, 46(3), 53-65.

Rafaeli, S., Barak, M., Dan-Gur, Y., \& Toch, E. (2004). QSIA-a webbased environment foe learning, assessing and knowledge sharing in communities. Computers and Education, 43, 273-289.

Richardson, J.C., \& Swan, K. (2003). Examining social presence in online courses in relation to students' perceived learning and satisfaction. $J A L N, 7(1), 68-88$

Rovai, A.P. (2002). Building a sense of community at a distance. International Review of Research in Open and Distance Learning, 3(1), 1-16. Available from: http://www.irrodl.org/index.php/irrodl/article/ view/79/152. [Last retrieved on 2018 Aug 02].

Rovai, A.P., \& Lucking, R.A. (2000). Measuring Sense of Classroom Community. Paper Presented at Learning 2000: Reassessing the Virtual University, Virginia Tech, Roanoke, VA.

Rovai, P.A., Wighting, J.M., Baker, J.D. \& Grooms, L.D. (2009) Development of an instrument to measure perceived cognitive, affective, and psychomotor learning in traditional and virtual classroom higher education settings. The Internet and Higher Education, 12(1), 7-13.

Shea, P., Li, C.S., \& Pickett, A. (2006). A study of teaching presence and student sense of learning community in fully online and web-enhanced college courses. Internet and Higher Education, 9(3), 175-190.

Steinkuehler, C.A., \& Williams, D. (2006). Where everybody knows your (screen) name: Online games as "third places". Journal of Computer Mediated Communication, 11, 885-909.

Szeto, E. (2015). Community of inquiry as an instructional approach: What effects of teaching, social and cognitive presences are there in blended synchronous learning and teaching? Computers and Education $81,191-201$

Temple, L., \& Lips, H. (1989). Gender differences and similarities in attitudes towards computers. Computers in Human Behavior, 5, 215-226.

Thirunarayanan, M.O., \& Prado, A.P. (2001). Comparing web-based and classroom-based learning. Journal of Research on Technology in Education, 34(2), 131-137.

Thompson, R.L., Higgins, C.A., \& Howell, J.M. (1991). Personal computing: Toward a conceptual model of utilization. MIS Quarterly, $15,125-143$

Triandis, H.C. (1971). Attitude and Attitude Change. New York: John Wiley.

Tsai, C.C. (2001). The interpretation construction design model for teaching science and its applications to internet-based instruction in Taiwan. International Journal of Educational Development, 21, 401-415. 
Tsai, C.C. (2008). The preferences toward constructivist internet-based learning environments among university students in Taiwan. Computers in Human Behavior, 24(1), 16-31.

Volet, S., Summers, M., \& Thurman, J. (2009). High-level co-regulation in collaborative learning: How does it emerge and how is it sustained? Learning and Instruction, 19(2), 128-143.

Ward, M., \& Newlands, D. (1998). Use of the web in undergraduate teaching. Computers and Education, 31(2), 171-184.

Warschauer, M. (2004). The rhetoric and reality of aid: Promoting educational technology in Egypt. Globalisation, Societies and Education, 2(3). Available from: http://www.gse.uci.edu/faculty/markw/rhetoric.pdf. [Last retrieved on 2016 Sep 28].

Weber, A. (2012). Considerations for social network site (sns) use in education. International Journal of Digital Information and Wireless Communications, 2(4), 37-52.

Wegerif, R. (1998). The social dimension of asynchronous learning networks.
Journal of Asynchronous Learning Networks, 2(1), 34-49.

Whitely, B.E.J. (1997). Gender differences in computer related attitudes and behavior: A meta analysis. Computers in Human Behavior, 13(1), 1-22.

Wu, Y.T., \& Tsai, C.C. (2006). University students' internet attitudes and internet self efficacy: A study at three universities in Taiwan. Cyber Psychology and Behavior, 9, 441-450.

Yaghi, H.M., \& Abu-Saba, M. (1998). Teacher's computer anxiety: An international perspective. Computers in Human Behavior, 14(2), 331-336.

Yang, F.Y., \& Tsai, C.C. (2008). Investigating university student preferences and beliefs about learning in the web-based context. Computers and Education, 50, 1284-1303.

Zhu, E., \& Baylen, D.M. (2005). From learning community to community learning: Pedagogy, technology and interactivity. Educational Media International, 42(3), 251-268. 